$\begin{gathered}\text { EPiC Series in Education Science } \\ \text { Volume 1, 2017, Pages 119-128 }\end{gathered}$
$\begin{aligned} & \text { AUBEA 2017: Australasian Universities Build- } \\ & \text { ing Education Association Conference 2017 }\end{aligned}$

\title{
The Core Functions of Project Governance
}

\author{
Eric Too ${ }^{1}$, Tiendung Le ${ }^{1}$, Patrick Weaver ${ }^{2}$ and Lynda Bourne ${ }^{3}$ \\ ${ }^{1}$ RMIT University \\ ${ }^{2}$ Mosaic Project Services Pty Ltd \\ ${ }^{3}$ Stakeholder Management Pty Ltd
}

\begin{abstract}
Research in the realm of projects is increasingly turning its focus on governance. Much has been written on the importance of good governance and the clear link between good governance and project success. However, few have delved into delineating the core functions of governance that is central to good governance. In this conceptual paper, we examine existing research ideas and concepts of project governance to develop a framework to add to the knowledge base of this subject. This paper proposes six core functions of project governance. They include (1) determining the objective, (2) determining the ethics, (3) creating the culture, (4) designing and implementing the governance structure, (5) ensuring accountability by management and (6) ensuring compliance. The framework described in this paper can provide guidance to organizations in the development of effective project governance to optimize the management of projects.
\end{abstract}

\section{Introduction}

Project-based organizations have become widespread organizational structures. Projects are becoming the main vehicle to achieve strategic objectives and beneficial change (Biesenthal \& Wilden 2014). Accordingly, much academic and practitioner attention has been dedicated to achieving a better understanding of the management and governance of projects. One of the major determinants of success is an effective project governance structure (Lechler \& Dvir 2010). Good project governance is a precondition for achievement of success and sustainable value for the organization and all the stakeholders involved (Beleiu \& Nistor 2015). However, project governance models have lagged developments in the project management literature (Zwikael \& Smyrk 2015). Although research on governance acknowledges and addresses the nature of governance across the various relevant organizational levels (Foss, Husted \& Michailova 2010; Too \& Weaver 2014), due to the multiple definitions of project governance found in literature, the exact nature of the project governance construct remains unclear.

The aim of this paper is to examine and explore the functions of project governance. To do this, we examine current literature on governance. Existing knowledge of governance and project 
governance could be enriched by drawing from the stream of literature addressing projects as temporary organizations (Engwall 2003) within the project management literature. This stream of research is likely to offer valuable insights into the governance of projects as it addresses the complex interplay between the stability of the project-based firm versus the inherent temporarily of the project (Ahola et al. 2014). We investigate how the concepts and themes of dominant corporate governance theories have been applied to the context of project governance. Synthesising these findings, we present a framework linking governance theories with the focus of project governance.

The paper begins with an overview of the relationship between project performance and governance that underlies the importance of governance research. This is followed by a review of the concept of governance and the diversity of views of project governance that warrant clearer descriptions of these governance functions. Based on this literature review, we propose a conceptual framework describing the key functions of project governance. We conclude this paper with a summary of our findings and discussion of future work.

\section{Theoretical Background}

There is a significant growth in the adoption of project management tools and techniques to accomplish work in different sectors and industries (Tsaturyan \& Müller 2015). The main purpose of using projects and their associated disciplines is to increase organizational value (Dalcher 2012). Project value refers to the explicit and implicit functions created by the project, which can satisfy the explicit and implicit needs of stakeholders (Zhai, Xin \& Cheng 2009). Therefore, project value can be understood in so far as it satisfies customer needs, aligns the project output with the organization's strategy and gives a return on investment (Thomas \& Mullaly 2007).

To measure the value created from using projects, governance is increasingly recognized as the key factor to achieve project success (Joslin \& Müller 2016; Lechler \& Dvir 2010; Muller 2009). Sanderson (2012) argues that performance problems are often a result of misaligned or underdeveloped governance mechanisms, which hinder project actors' ability to provide sufficiently flexible and robust response to inevitable turbulence. A good governance structure can therefore reduce conflicts among different groups of stakeholders and contributes to a firm's performance as it helps to manage and minimize project risk, improve transparency between different organizational levels (to meet project objectives), and positively influences the exchange of relevant information across different stakeholder groups (Muller 2009). In other words, good governance is a precondition for the achievement of success and creation of sustainable value to organizations and their stakeholders (Beleiu \& Nistor 2015). However, project governance models tend to lag other developments in the project management literature (Aubry, Monique, Richer \& Lavoie-Tremblay 2014; Zwikael \& Smyrk 2015).

Governance, in general, means 'to steer'. The Organization for Economic Co-operation and Development (OECD) defines governance as: "Involving a set of relationships between a company's management, its board, its shareholders and other stakeholders [...] and should provide proper incentives for the board and management to pursue objectives that are in the interests of the company and its shareholders and should facilitate effective monitoring" (OECD 2004). In its most general form it is defined as a set of rules, (stakeholder) relationships, systems and processes by which authority is exercised and controlled in organizations. It relates to processes and decisions that seek to define actions, grant power, and verify performance (Samset \& Volden 2016). Hence, "governance is ultimately concerned with creating the conditions for ordered rule and collective action" (Stoker 1998).

Projects are embedded within an organizational context. Within organizations, "governance of projects" concerns the areas of governance that are specifically related to project activities (APM 
2011; Biesenthal \& Wilden 2014; Too \& Weaver 2014). In fact, projects and project management coexist within the corporate governance framework and therefore refers to the processes, systems, and regulations that must be put in place to ensure that projects are successful and create value for the organization. To this end, project governance supports an organization in aligning its project objectives with its organizational strategy, achieving set project objectives and monitoring performance (PMI 2013; Turner 2009).

Project governance research has started to address governance across the various relevant organizational levels (Foss, Husted \& Michailova 2010). Many studies that examine project governance have attempted to provide the definitions of project governance. Some of these definitions indirectly specify the functions of project governance. Some studies discuss a small number of functions. For example, Pinto (2014) describes project governance as "the use of systems, structures of authority, and processes to allocate resources and coordinate or control activity in a project" Other studies have identified and described a very large number of functions. Hazard and Crawford (2004) define project governance as "a set of formal principles, structures and processes for the undertaking and management of projects, applicable in the context of individual projects, programs or portfolios of projects which appoint a governor (or governing body) for a project ; define and regulate roles, accountabilities, decision making and boundary management, and coordinate project relationships, planning and control. In between these extremes, there are studies discussing a moderate number of functions; for example, Turner (2009) defines project governance by referring to the relationships between the owner of the project, the sponsor, the project manager and other stakeholders.

In all these cases, many functions are found to be overlapping and interconnected. The diverse definitions within the literature, at least partially, are due to the studies being conducted on various types of organizations active in different industries, such as IT, telecommunications, construction and real estate and the healthcare sector. It is also clear that definitions of project governance are broad and vague, incorporating many empirically identified phenomena. Furthermore, the definitions generally do little to clarify the specific functions that the project governance undertakes. Many studies have also investigated project governance functions without conceptually distinguishing between them, or reflecting on how they relate to each other. Hence, even if a broad range of project governance functions have been investigated and numerous benefits are purported, the understanding of how these functions interact remains unclear.

In summary, research to-date indicates that there is a piecemeal understanding of project governance and a lack of alignment of definitions and scope, often mixing concepts like factors, mechanisms, enablers without clear distinctions. Some of the confusion around project governance research may have arisen because researchers attempt to merge various governance theories to find a single solution to the problem of project governance. This suggest there is clearly a lack of a shared and universally accepted view of what the functions of project governance are. Therefore, in this paper we present a conceptual framework, structured around the functions of governance that provides suggestions regarding how existing governance theories may best be applied to the context of project governance. Aligned with the aim of the paper, the following research question is addressed: What are the relevant functions for Project Governance?

\section{Findings and Discussions}

Governance is the action of governing an organization by using and regulating influence to direct and control the actions and affairs of management and others. It is the exclusive responsibility of the 'governing body', the person, or group accountable for the performance and conformance of the organization (in a commercial organization, the Board of Directors). The central element of project governance is, therefore, to understand the functions performed by the project governing body. 
Current literature does not agree on what constitutes a robust project governance model (Garland 2009). Despite the difference in emphasis, they share the views that project governance is simply concerned with aligning project objectives with an overarching organizational strategy, and that is necessary to create stakeholder value across the organizational network. Garland (2009) proposed four key principles for a good structure of project governance: (1) identify a single point of accountability, (2) ensure a service delivery focus, (3) separate the project and the organization governance structures, and (4) separate stakeholder management and project decision making. Based on these key principles, we conceptualize six functions of project governance (see Figure 1) that must be effectively carried out by a project governing board. They are discussed in detail below.

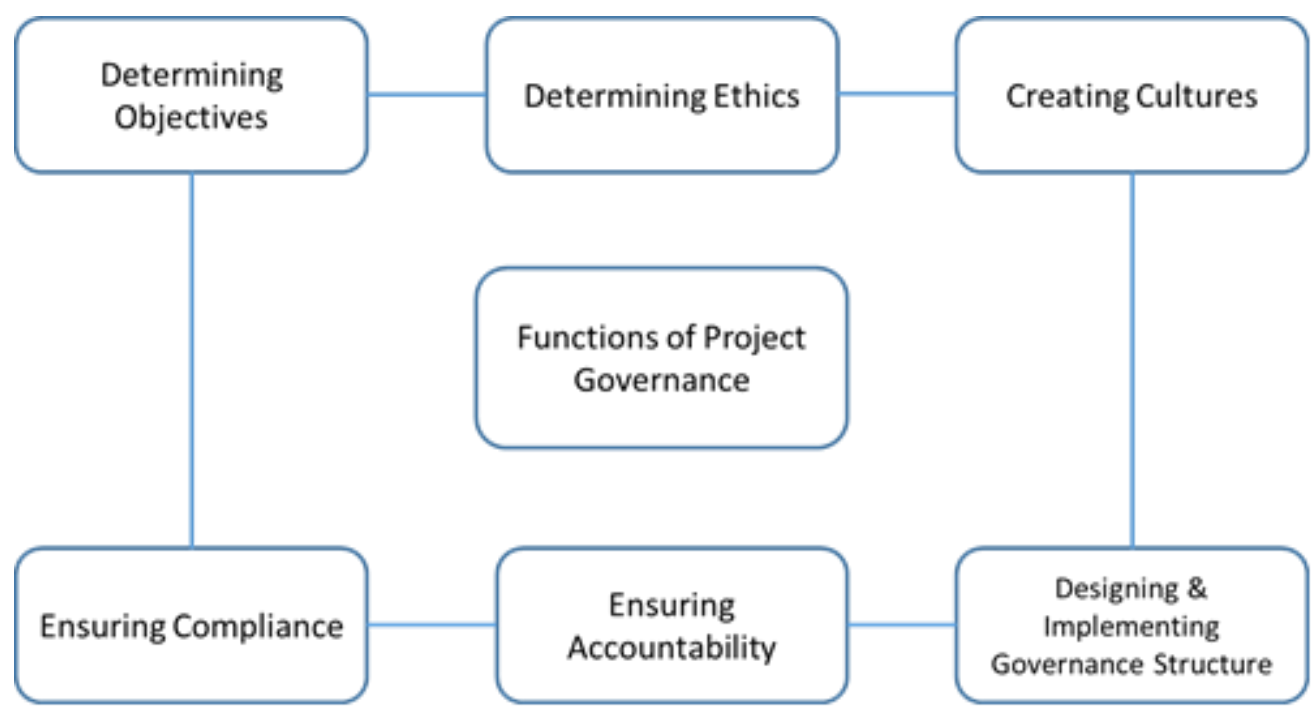

Figure 1: Functions of Project Governance

\subsection{Determining the objectives of the projects}

Project-based organisations participate in projects to fulfil their business interests and goals (Artto $\&$ Wikström 2005). As such, project goals mostly derive from the wider and more long-term strategic objectives (Swan, Scarbrough \& Newell 2010). In this way, the corporate strategy that represents the business interests of the parent organization in the project environment provides the basis for understanding how the project adds value to the organization in the form of outcomes and deliverables (Monteiro de Carvalho 2013). All definitions of project governance include setting project objectives and aligning them with an overarching organizational strategy, as an important element (e.g. see Muller 2009; PMI 2013; Turner 2009).

The objectives define the purpose of the project and describe how the purpose will be fulfilled. This function offering strategic management support can take many forms, such as participating in strategic planning and aligning the project portfolio with overarching strategic objectives (Aubry, M. et al. 2011). The objective setting function is a key interface between project management and the governing body:

- The governing body determines the project's objectives;

- There is shared responsibility to develop an effective strategy to achieve the objectives; 
- Project management is responsible for implementing the strategy through the efficient and effective use of the organization's limited resources.

In short, the primary purpose of project governance is to ensure that the project will meet the goals and expectations subjected to it by various stakeholders (Ahola et al. 2014). Hence, the core function of project governance is to determine the objectives of the project and to align it to work to deliver the broader strategic goals of the organization.

\subsection{Determining the project organization ethics}

Ethics has developed into an important topic for organizations and their governance (Müller \& Lecoeuvre 2014). Ethics are based on morals and values and define the rules or standards governing the conduct of people within the organization. Müller et al., (2013) found that managers of project organizations face different types of ethical issues, and that the way they respond to them can be influenced by the governance structure of the parent organization. The findings suggest that project managers' behaviours differ according to the governance structure.

The ethical standards of any projects are set by the behaviours of people at the top and cascade down the hierarchy. Some common ethical issues confronted the project managers include transparency, optimization, and relationship (Müller \& Lecoeuvre 2014), power and political issues, illegal actions, role conflicts. It is pertinent that the project governing body must determine the project ethics within the project governance structure to help project managers dealing with these issues. For example, by adjusting their governance paradigm toward more stakeholder orientation, organizations can increase the level of trust between project managers and the key people in the governance structure. Doing this may also enhance trust among other project actors (Müller et al. 2014).

\subsection{Creating the culture of the project organization}

Project organization culture is a subtle process and deals with the way people interact with one another. Culture is conceptualized as consistent, shared by all members, an objective entity, and a cohesive glue for integration processes (Alvesson 2002). It is the environment in which work gets done, and is embedded in the people working for the organization, it naturally evolves as a company grows or changes and requires continuous nurturing and management. Ouchi (1980) connects culture and governance by highlighting the role of a "clan" in the control of organizations. He defines a "clan" as a culturally homogeneous organization that has a shared set of values or objectives together with beliefs about how to coordinate the organization's effort to reach common objectives (Ouchi 1980).

Project performance problems are inevitable result of the organizational complexity, ambiguity, and conflict faced by project actors with diverse and competing project cultures and rationalities (Van Marrewijk et al. 2008). According to Sanderson (2012), even studies of project culture focus too much on facilitating trust and collaboration in the face of uncertainty (Atkinson, Crawford \& Ward 2006) and ignore spontaneous micro-processes of governing, which emerge ex post. Turner (2009) argues that governmentality, the willingness of people to 'be governed' and to support the governance system, is at the centre of an effective culture. Hence, project governance becomes the means to acquire order, so that the stakeholders can recognize the common interests among the underlying threats and chances. Other aspects of culture include how supportive the organization is, how innovative, how risk seeking/averse, how open and transparent, how mature and professional, and how tolerant it is. It is pertinent, therefore, for the governing body to determine the culture it wishes to create and influence the operating culture of the organization through the people it appoints to executive positions. 


\subsection{Designing and implementing the project governance structure for the project organization}

Having determined the project objectives, the ethics and cultures of the project organizations, a governance structure consisting of shared coordination, control, and safeguarding mechanisms needs to be put in place to align the interests of multiple organizational actors to work towards a joint goal (Ahola et al. 2014). To achieve and manage effective cooperation between the key actors and elements, the interdependence between them should be structured and defined (Golden \& Martin 2004) in order to realise benefits from intended projects (Zwikael \& Smyrk 2015). Likewise, the interdependence between roles, responsibilities and accountabilities should be clarified prior to the start of a project (Ahola et al. 2014; Too \& Weaver 2014) so that the cognitive conflicts over the responsibilities and areas of accountability between these roles can be reduced (Forbes \& Milliken 1999) and, therefore, project success is improved through the cohesiveness in the governance of the structure.

A central element of good project governance is decision rights (Nault 1998), which are defined as decision-making authority (Dessein 2002). This involves developing a set of relationships among partners, sponsors, contractors, client and other stakeholders (Lu et al. 2015; OECD 2004) and the determination of roles, responsibilities and accountabilities among stakeholders to achieve an ethical, cohesive and transparent decision making process for the sake of achieving the mission of the project organization (Badewi 2015).The key function of project governance body is therefore to propose a project governance structure that combines processes, roles and accountabilities aimed at delivering projects (Biesenthal \& Wilden 2014). Good project governance structure can also serve as a mean in which poorly performing projects are highlighted and early warning signs trigger an alert mechanism (Biesenthal \& Wilden 2014).

\subsection{Ensuring accountability by project management}

Successful projects contribute to the broader strategic goals on a program or portfolio level of the organization (Williams \& Samset 2012). Project management is thus a component of project governance at the project level that deals with the operational control and execution of the daily project work at the project level (Turner 2009). Project governance at the project level has a direct effect on project management and the delivery of project-specific objectives to a broader set of stakeholders (Bredillet 2008). Hence the primary role of project governance is to establish a shared set of rules and procedures that all firms participating to the project are expected to follow (Ahola et al. 2014). In the context of projects, these rules include the definition and regulation of roles, accountabilities, decision making and boundary management (Mosavi 2014).

Joslin and Müller (Joslin \& Müller 2015) suggest that project governance has an oversight function which collectively encompasses the project lifecycle to ensure a consistent approach to controlling the project with the aim of ensuring its success. Monitoring and ensuring accountability of project performance is, therefore, a common project governance function (e.g. Biesenthal \& Wilden 2014; Muller 2009; Too \& Weaver 2014; Turner 2006). It has also been argued that the task of monitoring and controlling project to achieve project goals is allocated to decision making bodies who meet on a regular basis to review and make certain decisions including:

- the ethical and cultural environment are maintained within the organization;

- the stewardship and proper use of the resources entrusted to their care; and

- the accomplishment of the strategic plan and fulfilment of the organizations objectives.

The governing body is accountable for the performance of the project organization, and retains overall responsibility for the project organization it governs. However, in most project organisations 
the governing body cannot undertake all the work of governance itself. To ensure the effective governance of the project organization, various responsibilities need to be delegated to people within the project organization's management (Too \& Weaver 2014).

\subsection{Ensuring compliance by the organization}

The aim of project governance is the consistent and predictable delivery of the project's planned contribution to the portfolio and thereby to the achievement of corporate strategic objectives within a corporate governance framework. Following this view, the purpose of project governance is both to define standards or rules that individual projects are expected to comply with, and to monitor the fulfilment of these rules (Ahola et al. 2014). To achieve this, a key function of the project governance board is to ensure the compliance of formal rules (Lusch \& Brown 1996). Miller and Lessard (2001) explain that the organizational structure of a project, the shaping of the project, the project's institutional framework and the capacity of self-regulation are essential features of governance. Central to this function is providing relevant stakeholders with:

- assurance of the organization's compliance with its regulatory, statutory and legal obligations;

- monitoring and directing the performance of its management and staff as they work towards achieving the organization's objectives;

- working within the organization's ethical and cultural framework; and

- $\quad$ supporting the values established by the governing body.

\section{Conclusions}

The growing number of project governance-related papers indicates that project governance is an increasingly important topic. The aim of this paper is to understand the key functions of project governance through a systematic review of project governance literature.

We have found several specific themes and concepts that imply the functions of project governance. The key central functions of project governance identified are: (1) determining the objectives of the project and aligning it to work together towards the broader strategic goals of the organization; (2) determining the project ethics within the governance structure to help project managers dealing with ethics issues; (3) determining the culture it wants and influencing the operating culture of the organization through the people it appoints to executive positions; (4) developing and implementing a project governance structure to realize the benefits from projects; (5) monitoring and ensuring accountability of project performance; and (6) providing relevant stakeholders with assurance of the organization's compliance with its regulatory, statutory and legal obligations.

The proposed conceptual framework describes the key functions that project governance body should carry out to ensure effective governance and hence to ensure value be created from the work and outcomes of projects. Looking ahead and to further validate this framework, we encourage case studies on how project governance functions can be operationalized to create value for organizations. In addition, a large-scale empirical test of how different configurations of functions affect performance in different empirical contexts is encouraged. Furthermore, it is worth investigating the contextual characteristics that govern the suitability of adopting these functions in managing projects. 


\section{References}

Ahola, T, Ruuska, I, Artto, K \& Kujala, J 2014, 'What is project governance and what are its origins?', International Journal of Project Management, vol. 32, no. 8, pp. 1321-32.

Alvesson, M 2002, Understanding Organization Culture, Sage, London.

APM 2011, Directing change: A guide to governance of project management, Association for Project Management, UK.

Artto, KA \& Wikström, K 2005, 'What is project business?', International Journal of Project Management, vol. 23, no. 5, pp. 343-53.

Atkinson, R, Crawford, L \& Ward, S 2006, 'Fundamental uncertainties in projects and the scope of project management', International Journal of Project Management, vol. 24, no. 8, pp. 687-98.

Aubry, M, Richer, M-C \& Lavoie-Tremblay, M 2014, 'Governance performance in complex environment: The case of a major transformation in a university hospital', International Journal of Project Management, vol. 32, no. 8, pp. 1333-45.

Aubry, M, Richer, M-C, Lavoie-Trembley, M \& Cyr, G 2011, 'Pluralism in PMO performance: The case ofa PMO dedicated to a major organizational transformation', Project Management Journal, vol. 42, no. 6, pp. 60-77.

Badewi, A 2015, 'The impact of project management (PM) and benefits management (BM) practices on project success: Towards developing a project benefits governance framework', International Journal of Project Management.

Beleiu, I \& Nistor, R 2015, 'Project governance and its contribution to projects; success', Managerial Challenges of the Contemporary Society, vol. 8, no. 1, pp. 82-6.

Biesenthal, C \& Wilden, R 2014, 'Multi-level project governance: Trends and opportunities', International Journal of Project Management, vol. 32, no. 8, pp. 1291-308.

Bredillet, CN 2008, 'Exploring research in project management: nine schools of project management research (Part 6)', Project Management Journal, vol. 39, no. 3, pp. 2-5.

Dalcher, D 2012, 'Project management for the creation of organisational value', Project Management Journal, vol. 43, no. 3, p. 79.

Dessein, W 2002, 'Authority and communication in organizations', Review of Economic Studies, vol. 69 , no. 4, pp. 811-38.

Engwall, M 2003, 'No project is an island: linking projects to history and context.', Research Policy, vol. 32, no. 5, pp. 789-808.

Forbes, DP \& Milliken, FJ 1999, 'Cognition and corporate governance: understanding boards of directors as strategic decision-making groups', Academic Management Review, vol. 24, no. 3, pp. 489505.

Foss, NJ, Husted, K \& Michailova, S 2010, 'Governing knowledge sharing in organizations: levels of analysis, governance mechanisms, and research directions.', Journal of Management Studies, vol. 47, pp. 455-82.

Garland, R 2009, Project governance: a practical guide to efficient project decision-making, Kogan Page, London.

Golden, BR \& Martin, RL 2004, 'Aligning the stars: using systems thinking to (re)design Canadian healthcare.', Healthcare Quarterly, vol. 7, no. 4, pp. 24-42.

Hazard, V \& Crawford, LH 2004, 'Defining project governance', paper presented to ProMAC Research Conference, Tokyo.

Joslin, R \& Müller, R 2015, 'Relationships between a project management methodology and project success in different project governance contexts', International Journal of Project Management, vol. 33, no. 6, pp. 1377-92.

---- 2016, 'The relationship between project governance and project success', International Journal of Project Management, vol. 34, no. 4, pp. 613-26. 
Lechler, T \& Dvir, D 2010, 'An alternative taxonomy of project management structures: linking project management structures and project success',

IEEE Transactions on Engineering Management, vol. 57, no. 2, pp. 198-210.

Lu, P, Guo, S, Qian, L, He, P \& Xu, X 2015, 'The effectiveness of contractual and relational governances in construction projects in China', International Journal of Project Management, vol. 33, no. 1, pp. 212-22.

Lusch, RF \& Brown, JR 1996, 'Interdependency, contracting, and relational behavior in marketing channels', Journal of Marketing, vol. 60, no. 4, pp. 19-38.

Miller, R \& Lessard, D 2001, The strategic management of large engineering projects: Shaping risks, institutions and governance MIT Press, Cambridge, MA.

Monteiro de Carvalho, M 2013, 'An investigation of the role of communication in IT projects.', International Journal of Operations \& Production Management, vol. 34, no. 1, pp. 36-64.

Mosavi, A 2014, 'Exploring the roles of portfolio steering committees in project portfolio governance', International Journal of Project Management, vol. 32, no. 3, pp. 388-99.

Muller, R 2009, Project governance, Gower, London.

Müller, R, Andersen, ES, Kvalnes, ö, Shao, J, Sankaran, S, Turner, JR, Biesenthal, C, Walker, D \& Gudergan, S 2013, 'The Interrelationship of Governance, Trust, and Ethics in Temporary Organizations', Project Management Journal, vol. 44, no. 4, pp. 26-44.

Müller, R \& Lecoeuvre, L 2014, 'Operationalizing governance categories of projects', International Journal of Project Management, vol. 32, no. 8, pp. 1346-57.

Müller, R, Turner, R, Andersen, ES, Jingting, S \& Kvalnes, Ø 2014, 'Ethics, Trust, and Governance in Temporary Organizations', Project Management Journal, vol. 45, no. 4, pp. 39-54.

Nault, B 1998, 'Information technology and organization design: Locating decisions and information', Management Science, vol. 44, no. 10, pp. 1321-35.

OECD 2004, OECD principles of corporate governance 2004, OECD Publication Services, $<$ http://www.oecd.org. $>$.

Ouchi, WG 1980, 'Markets, bureaucracies, and clans.', Administrative Science Quarterly, vol. 25, no. 1 , pp. 129-41.

Pinto, JK 2014, 'Project management, governance, and the normalization of deviance', International Journal of Project Management, vol. 32, no. 3, pp. 376-87.

PMI 2013, A Guide to the Project Management Body of Knowledge 5th Ed, Project Management Institute, Newton Square, PA

Samset, K \& Volden, GH 2016, 'Front-end definition of projects: Ten paradoxes and some reflections regarding project management and project governance', International Journal of Project Management, vol. 34, no. 2, pp. 297-313.

Sanderson, J 2012, 'Risk, uncertainty and governance in megaprojects: A critical discussion of alternative explanations', International Journal of Project Management, vol. 30, no. 4, pp. 432-43.

Stoker, G 1998, 'Governance as theory: five propositions', International Social Science Journal, vol. 155, pp. 17-28.

Swan, J, Scarbrough, H \& Newell, S 2010, 'Why don't (or do) organizations learn from projects?', Management Learning, vol. 41, no. 3, pp. 325-44.

Thomas, J \& Mullaly, M 2007, 'Understanding the Value of Project Management: First Steps on an International Investigation in Search of Value', Project Management Journal, vol. 38, no. 3, pp. 74-89.

Too, EG \& Weaver, P 2014, 'The management of project management: A conceptual framework for project governance', International Journal of Project Management, vol. 32, no. 8, pp. 1382-94.

Tsaturyan, T \& Müller, R 2015, 'Integration and governance of multiple project management offices (PMOs) at large organizations', International Journal of Project Management, vol. 33, no. 5, pp. 1098-110. 
Turner, JR 2006, 'Towards a theory of project management: The nature of the project governance and project management', International Journal of Project Management, vol. 24, no. 2, pp. 93-5.

---- 2009, The Handbook of project-based management, McGraw Hill.

Van Marrewijk, AH, Clegg, S, Pitsis, T \& Veenswijk, M 2008, 'Managing public-private megaprojects: paradoxes, complexity and project design', International Journal of Project Management, vol. 26, no. 6, pp. 591-600.

Williams, TM \& Samset, K 2012, Project Governance: Getting Investments Right, Palgrave Macmillan, Hampshire.

Zhai, L, Xin, Y \& Cheng, C 2009, 'Understanding the value of project management from a stakeholder's perspective: Case study of mega-project management', Project Management Journal, vol. 40, no. 1, pp. 99-109.

Zwikael, O \& Smyrk, J 2015, 'Project governance: Balancing control and trust in dealing with risk', International Journal of Project Management, vol. 33, no. 4, pp. 852-62.

ww.ctan.org/tex-archive/ help/Catalogue/entries/graphicx.html

Voronkov, A. (2004). EasyChair conference system. Retrieved from easychair.org

Voronkov, A. (2014). Keynote talk: EasyChair. In Proceeedings of the 29th ACM/IEEE International Conference on Automated Software Engineering (pp. 3-4). ACM.

Wikipedia. (n.d.). EasyChair. Retrieved from Wikipedia: https://en.wikipedia.org/wiki/EasyChair 